Journal of Research in International Business and Management (ISSN: 2251-0028) Vol. 5(1) pp. 74-80,

August 2018

Available online http://www.interesjournals.org/JRIBM

DOI: http:/dx.doi.org/10.14303/jribm.2018.017

Copyright $\odot 2018$ International Research Journals

Full Length Research Paper

\title{
Volatility, market capitalization and seasonality of Bitcoin prices
}

\author{
Agnihotri M \\ Skyline University College, Sharjah, United Arab Emirates \\ *Corresponding Author's Email: maheshagni55@gmail.com
}

\section{Abstract}

\begin{abstract}
Financial markets have witnessed a tremendous growth of crypto currencies in the recent years. These crypto currencies are digital currencies and use encryption techniques to regulate the generation of units of currency and verify them. A number of crypto currencies are being traded in the markets which include Bitcoin. Bitcoin is the first and the most popular crypto currency traded in the markets. The price of Bitcoins has seen ups and downs in the last 8 years since its launch. The aim of this study is to study the volatility, market capitalization and seasonality of Bitcoins. The study uses only secondary data for a period of 6 years, for Volatility of Bitcoin prices, market capitalization and movement of Bitcoin prices, but 7 years for studying the seasonality of Bitcoin prices. Regression analysis, histograms are used to analyze and present the data. The findings of the study indicate the prices of Bitcoins have declined in the recent periods and have a tendency to decline during a certain period of the year.
\end{abstract}

Keywords: Crypto currencies, Bitcoin, Volatility, Market capitalization, Seasonality.

\section{INTRODUCTION}

Crypto currencies are digital currency which use encryption techniques to regulate the generation of units of currency and verify the transfer of funds, without involving banks.

The financial markets across the globe have witnessed a number of crypto currencies since 2009, the first crypto currency being Bitcoin. At the end of March, 2018, there are 1594 crypto currencies and 10,661 markets. https://coinmarketcap.com 
The first and the most traded crypto currency Bitcoin has been showing the volatile trend since July 2010 when it was first traded. The number of Bitcoins in circulation are 16,928,925 whereas the users are 421,647. The number of Bitcoin transactions reported as on 21 March, 2018 were 305,613,369. Trading in crypto currencies, financial instruments and other Initial Currency Offers, carry risk. Wild speculation in the financial assets lead to systematic risk and Bitcoin is no exception. Ever since it was first traded, the Bitcoin has seen ups and downs in the prices due to various reasons. This paper is an attempt

1. To study on the volatility of Bitcoin prices for a period of 5 years.

2. To understand the market capitalization of bitcoins and other crypto currencies for 5 years.

3. To throw light on movement of Bitcoin prices in USD and the advances and declines.

4. To predict the trends in the seasonality of Bitcoin prices.

The data for the purpose of study has been collected mainly from secondary sources including research journals and websites.

\section{REVIEW OF LITERATURE}

There are several studies conducted on the volatility of Bitcoins. In the paper "The economics of Bitcoin Price formation", Ciaian et al. (2014) studied the relationship between the price of Bitcoin and the demand and supply fundamentals of this crypto currency, some global financial indicators (oil price and the Dow Jones index) and Bitcoin's attractiveness for investors. The study discussed whether the macro financial developments are driving Bitcoin price in the long run and found that hat market forces and Bitcoin attractiveness for investors and users have a significant impact on Bitcoin price but with variation over time. "Virtual currency, tangible return: Portfolio diversification with bitcoin" Marie Brière, et al (2015) the authors analyzed a BTC investment from the standpoint of a US investor with a diversified portfolio including both traditional assets (worldwide stocks, bonds, hard currencies) and alternative investments (commodities, hedge funds, real estate). They observed that BTC had highly distinctive features, high average return and volatility.

Thomas Callburn (2018) in his study on the topic "Bitcoin research update: sentiment, seasonality and technical", stated that there is a negative seasonality in Q1.

Bitcoins as an investment or speculative vehicle? A first look by C. Baek and M. Elbeck (2014) in their article in Applied Economic Letters, the authors used Bitcoin and S\&P 500 Index daily return data to examine relative volatility using de trended ratios. Volatility estimation for Bitcoin: A comparison of GARCH models By Paraskevi Katsiampa (2017) explored the optimal conditional heteroskedasticity model with regards to goodness-of-fit to Bitcoin price data.

\section{Data collection}

The data for the purpose of study has been collected mainly from secondary sources including research journals and websites.

\section{Analysis}

The growth of Bitcoin could be attributed to Silk Road (on line parallel market), a digital platform, which needed a currency that could clear the transactions without the use of banks. In terms of market capitalization,

Bitcoin is currently the largest crypto currency, using block chain technology, followed by Ethereum, Ripple, Bitcoin cash, Cardano and Litecoin. 
The recent months, the financial markets have witnessed significant volatility $(\$ 20,000$ highest in December $2017)$ and ( $\$ 6,000$ in February 2018) in the Bitcoin prices. But the top crypto currencies move independently of one another. Many investors have made huge money in the early stages, by following the strategy buy low and sell high.

Table 1: Volatility of Bitcoin prices for the period March, 2012-March 2018.

\begin{tabular}{lllll}
\hline Date & Price & Date & Price & \% Change \\
\hline Mar-12 & 5.4 & Oct-12 & 12.9 & 138.88 \\
Oct-12 & 12.9 & Mar-13 & 93 & 620.93 \\
Mar-13 & 93 & Oct-13 & 200.6 & 115.69 \\
Oct-13 & 200.6 & Mar-14 & 685 & 221.38 \\
Mar-14 & 685 & Oct-14 & 405.8 & -40.75 \\
Oct-14 & 405.8 & Mar-15 & 248.8 & -38.68 \\
Mar-15 & 248.8 & Oct-15 & 336 & 35.04 \\
Oct-15 & 336 & Mar-16 & 442.8 & 31.78 \\
Mar-16 & 442.8 & Oct-16 & 724 & 63.64 \\
Oct-16 & 724 & Mar-17 & 1328.8 & 83.53 \\
Mar-17 & 1328.8 & Oct-17 & 6472.1 & 387.04 \\
Oct-17 & 6472.1 & Dec-17 & 19891 & 209.32 \\
Dec-17 & 19891 & Mar-18 & 11696 & -61.51
\end{tabular}

Volatility of Bitcoin prices for the period March, 2012 - March 2018

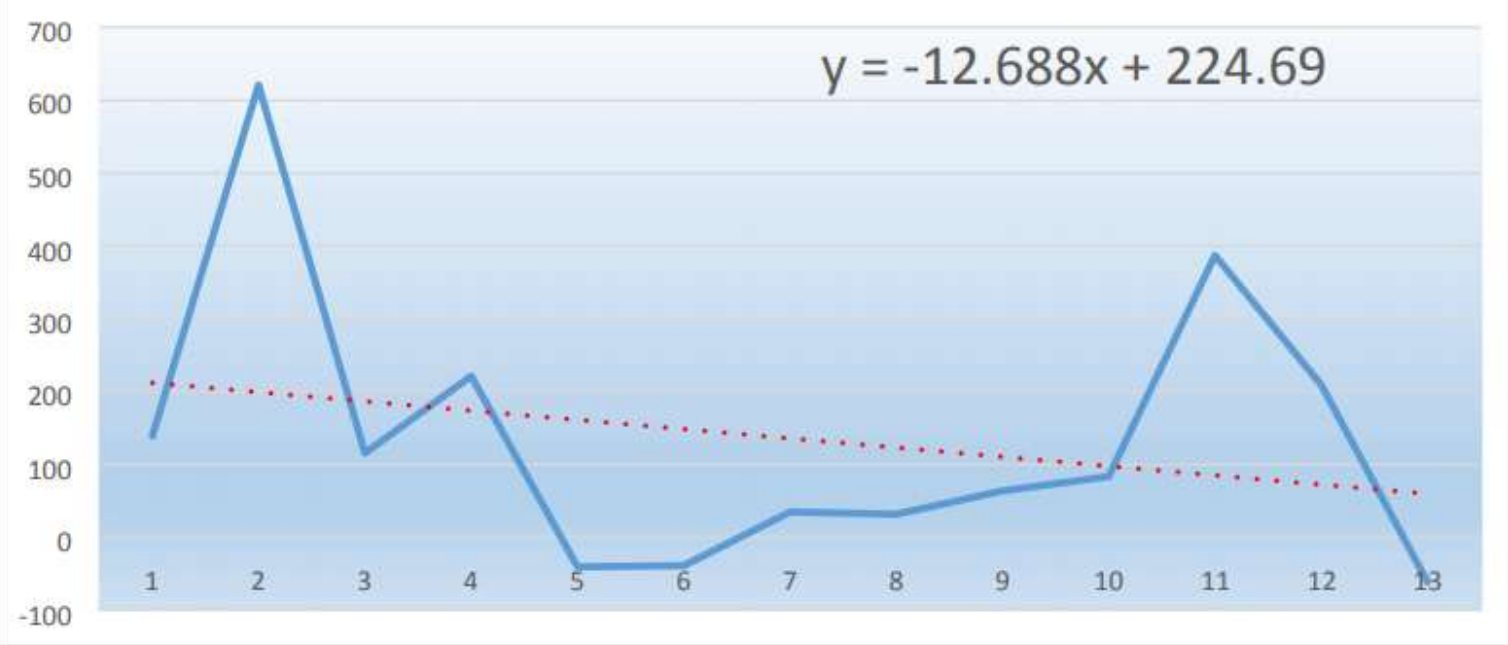

Figure 1: A graph indicating the mean prices of Bitcoins which constantly declined and likely to go down further.

Source: https://99bitcoins.com/price-chart-history 
Table 1 shows the prices of Bitcoins as on certain dates during the period March 2012 and October 2017. Bitcoin price hit all time high just below $\$ 19891$ on December 18, 2017 and in March 2018, it tumbled to $\$ 11696$ after South Korea announced measures to regulate the trading of Bitcoin, including shutting down of exchanges. The graph indicates that the mean prices of Bitcoins have constantly declined and likely to go down further.

The prices shown above indicate that the Bitcoin prices have been showing a fluctuating trend, with maximum rise of $(620.93 \%)$ which may have attributed to the European sovereign-debt crisis which may have been resulted in the funds diverted to investment in crypto currencies including Bitcoins.

This demonstrates the growth of Bitcoin was high in the beginning of the period, but as the time progressed the increase or the decrease has not been so significant. attributed to, the speed of the medium of exchange, lack of central command, several ways to buy or trade, the so called trusted exchanges and the cost of transactions.

Figure 1 indicates that the mean prices of the Bitcoin have been on the decline from March 2012 to December, 2017. The regression equation

$y=12.688 x+224.69$ predicts that the prices are going to decline further in the next period as well.

The decline particularly in the period from January, 2018 to March, 2018 is attributed to the ongoing changes in the regulations of the crypto currencies and Bitcoins. Its vulnerability to cyber-attacks is one of the major reasons for the declines in the price of the bitcoins.

Further the numerous fundamental developments surrounding the Bitcoin have also resulted in the decline of the Bitcoin which include, data hacking, cyber heist and increase in the cost of transactions.

\section{Market capitalization}

Table 2 given below showing the comparison of market capitalization of Bitcoins and other crypto currencies.

Table 2: Comparison of market capitalization of Bitcoins and other crypto currencies.

\begin{tabular}{|c|c|c|c|c|c|}
\hline Dates & $\begin{array}{l}\text { BTC (\% of } \\
\text { total market) } \\
\text { (launched in } \\
\text { 2009) }\end{array}$ & $\begin{array}{l}\text { ETH (\% of total } \\
\text { market) } \\
\text { (launched in } \\
2015)\end{array}$ & $\begin{array}{l}\text { BCH (\% of total } \\
\text { market) } \\
\text { (launched in Aug } \\
2017 \text { ) }\end{array}$ & $\begin{array}{l}\text { LTC (\% of total } \\
\text { market) } \\
\text { (launched in Oct } \\
2017 \text { ) }\end{array}$ & $\begin{array}{l}\text { XRP (\% of total } \\
\text { market) } \\
\text { launched in } \\
2012\end{array}$ \\
\hline \multicolumn{6}{|l|}{ 28th April } \\
\hline 2013 & 94.29 & 0 & & 4.62 & 0 \\
\hline \multicolumn{6}{|l|}{ 25th April } \\
\hline 2014 & 90.72 & 0 & 0 & 4.75 & 0.65 \\
\hline \multicolumn{6}{|l|}{ 28th April } \\
\hline 2015 & 87.56 & 0 & 0 & 1.45 & 6.73 \\
\hline \multicolumn{6}{|l|}{ 26th April } \\
\hline 2016 & 83.98 & 6.87 & 0 & 2.13 & 2.9 \\
\hline \multicolumn{6}{|l|}{ 26th April } \\
\hline 2017 & 66.65 & 14.73 & 0 & 2.83 & 3.97 \\
\hline \multicolumn{6}{|l|}{ March } \\
\hline 2018 & 41.65 & 18.25 & 4.64 & 2.5 & 8.3 \\
\hline
\end{tabular}




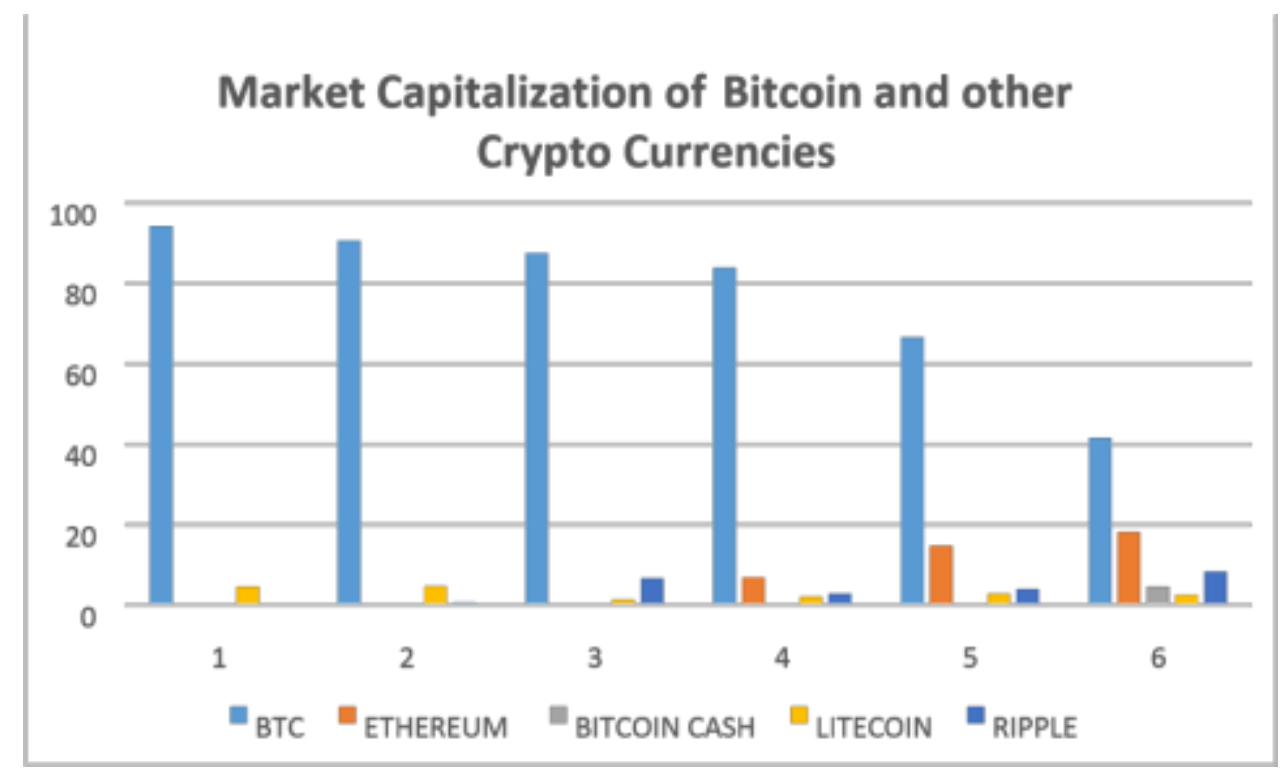

Figure 2: Market capitalization of Bitcoins and other crypto currencies.

Source: https://coinmarketcap.com

As it was the first Crypto currency, Bitcoin's market capitalization has been having a lion's share of the total crypto currencies market capitalization.

As the time passed by, Bitcoins market capitalization showed a declining trend from April 2013(94.29\%) to March, 2018 (41.65)

A decline of $52 \%$ during the period. This could be attributed to the advent of the other crypto currencies in the market which included, Ethereum, Bitcoin cash, Litecoin and Ripple.

The market capitalization of Ethereum has shown an upward trend whereas the other crypto currencies Litecoin and Ripple have shown a fluctuating trend.

It can be concluded that there is an inverse relationship/ negative correlation between the market capitalization of Bitcoin and Ethereum.

Movement of Bitcoin prices in USD and advances and declines during the period March 2012-March 2018

Table 3: Showing the movement of Bitcoin prices in USD and advances and declines during the period March 2012-March 2018.

Changes in the data for the period from March, 2012 to March 2018

Maximum advance in \%

461.14

Minimum advance in \%

0.03

Maximum decline in \%

Minimum decline in \% 
/ no of declines)

Highest price in \$

Lowest price in \$

Difference in price between highest and lowest in \$

The above data has been compiled from the records of Bitfinex for the period from March 2012 to March 2018 (Table 3).

It is evident from the above that, the Bitcoin price has seen a Maximum advances in the prices of Bitcoin was $461.14 \%$ during the month of November, 2013. Whereas the maximum decline reported one month later (December) was $34.58 \%$. This is a significant decline if one has to compare with the stock prices of corporates in any stock market in the world. The minimum advance and decline in the prices of Bitcoins has been as

low as $(.30 \%)$ and $(.83 \%)$ respectively, which seems to be in line with other financial stocks of corporates.

The average advances and declines have been reported at (36.21\%) and (11.34\%) respectively.

Based on the data for the period from March, 12 to March 2018, it can be stated that the average change in $\$$ has been 1376.6 where as a whopping change in the prices is shown at $186,603.6$.

This demonstrates the extent of volatility of the prices of bitcoins.

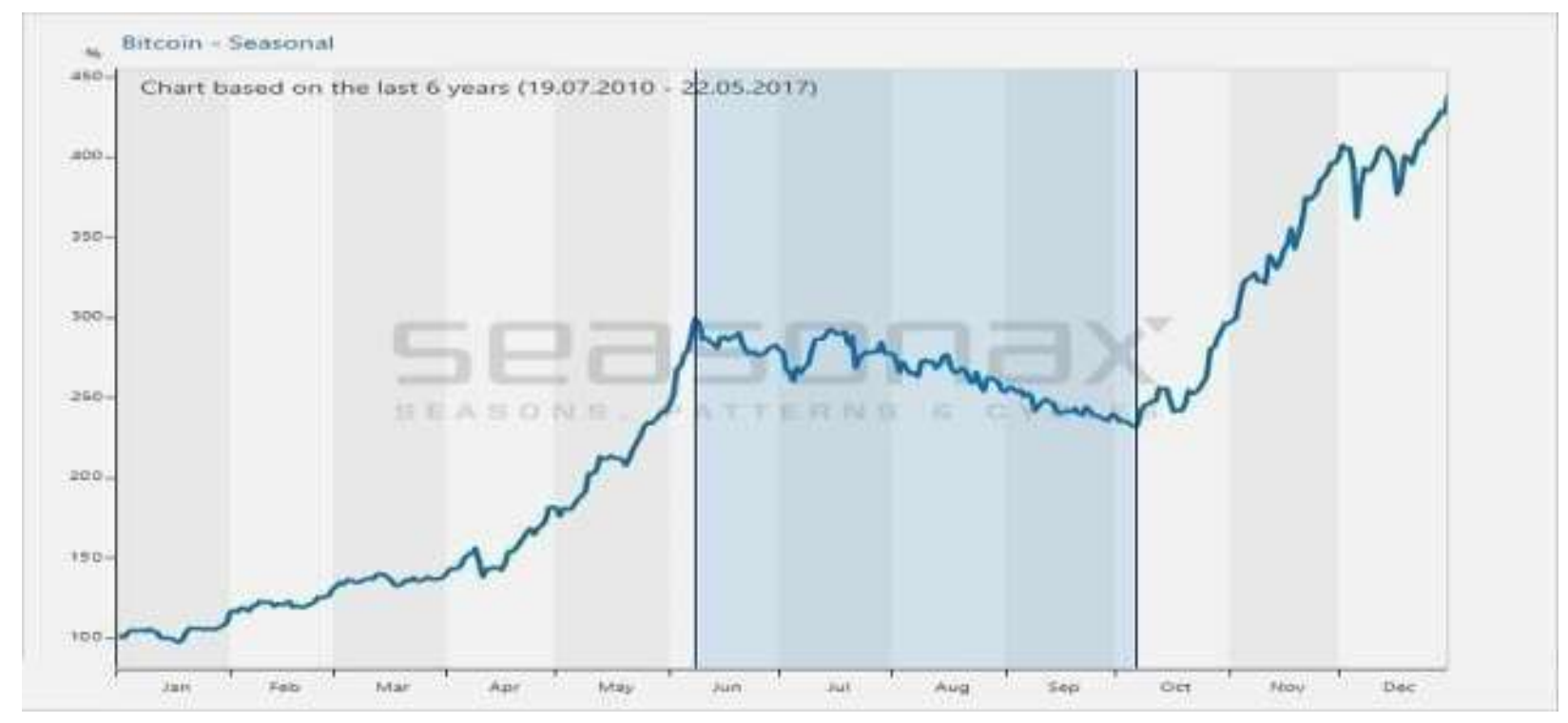

Figure 3: Seven-year seasonality of Bitcoin prices for the period December 2010-2017.

Source: Seasonax.

Seasonality is a phenomenon where price undergoes similar and predictable changes around the same period within every calendar year. These changes can happen in a specific meteorological season, growing 
season, quarter, month, holiday period or off-peak period.

The chart one given shows the price changes during the period of June 8 through October 6 th every year. The above chart depicts the average price pattern of the Bitcoin over the course of a year. The horizontal axis denotes the time of the year, the vertical axis denotes the level of seasonal index.

The average decline in the Bitcoin prices during the period June 8 and October, 6 over the past 7 years was $22.18 \%$ (annualized $55.23 \%$ )

On the other hand, the period from 6 October and June 8 Bitcoin prices rose by an average of $494.74 \%$ $(1,326.86 \%$ annualized $)$

This demonstrates the seasonality of prices even in the crypto currency Bitcoin as we generally witnessed in the traditional financial markets and in the prices of commodities.

Thus going by the seasonality point of view, it can be stated that it is time to sell the Bitcoins and buy during the period of 8 th June to 6th October.

\section{CONCLUSION}

The prices of Bitcoins have been declining in the recent months. This is due to the following reasons

1. The Governments of a number of counties are making amendments in the trading regulations.

2. Bitcoin as a crypto currency is facing technology risks.

3. The demand for Bitcoin has declined and the supply has increased in view of the above risks.

Given the amount of transparency and the other advantages in the form of speed and cost of transaction, it is expected that the prices of bitcoins may go up again.

\section{REFERENCES}

https://www.investing.com/crypto/bitcoin/btc-usdhistoricaldata

https://99bitcoins.com/price-chart-history/

Coin Market (2018) https://coinmarketcap.com/charts

http://www.acting-man.com/?p=49490

https://seeitmarket.com/bitcoin- researchupdateseasonalitysentiment-and-technicals-17947/5

Briere M, Oosterlinck K and Szafarz A (2015). Virtual Currency, Tangible Return: Portfolio Diversification with Bitcoin. Journal of Asset Management, 16 (6) 365-373.

Katsiampa P (2017). Volatility estimation for Bitcoin: A comparison of GARCH models Economics Letters 158: 3-6.

Baek C, Elbeck M (2014). Bitcoins as an investment or speculative vehicle? A first look. Applied Economics Letters vol. 22: 30-34

https://www.quandl.com/collections/markets/bitcoin-data

https://www.seeitmarket.com/bitcoin-research-update-seasonality-sentiment-and-technicals-17947/ 